\section{Glycogen Synthesis from Pyruvate in Muscle}

UNDER normal conditions glucose is the major source of muscle glycogen. In muscle, pyruvate and lactate make only a minimal contribution to glycogen but the liver can freely convert these compcunds into glycogen ${ }^{1,2}$. One of the key enzymes in the process of glycogenesis in liver is fructose-1,6-diphosphatase (FDPase) ${ }^{3}$, and the inability of muscle to convert pyruvate to glycogen was attributed to its absence, ${ }^{4,5}$. Recently, however, Krebs and Woodford $^{6}$ have shown that the enzyme does occur in striated muscle, so that at least one of the energy barriers in the conversion of pyruvate to glyeogen is now known to be surmountable.

The possibility that muscle might be able to synthesize glycogen from pyruvate and lactate had to be considered when it was observed that the glycogen content of muscle, obtained from patients suffering from liver glycogen storage disease due to glucose-6-phosphatase (G-6-Pase) deficiency, was moderately but significantly greater than normal (Table I).

In such patients glycogen is structurally normal and there is no enzymatic hindrance to the broakdown and removal of muscle glycogen. The observation was all the more unexpected because the blood sugar of these patients is low; on the other hand, the blood level of pyruvate and lactate is always high ${ }^{7,8}$ (Table 1). It scemed possible, therefore, that under these circumstances these two compounds might become a source of musclo glyeogen.

The supposition was supported when it was observed that considerably more radioactivity from labelled pyruvate was incorporated into the patients' muscle glyeogen than into normal musele glycogen (Table 2 ).

Additional evidence came from the assay of FDPase activity (Table 3 ) using the method described by McGilvery $^{9}$. Some activity was detected in normal muscle but it was much greater in the muscle obtained from the patients, thus confirming the potential ability of muscle to form new glycogen from 3-carbon precursors.

For comparison, the results of analyses of muscle obtained from 2 patients suffering from a primary muscle glycogen storage disease, due to phosphorylase deficiency ${ }^{\mathbf{1 0}}$, are included in the tables. These patients do not have elevated plasma lactate and pyruvate lovels and although their muscles contain more than the normal amount of glycogen, they bchave like normal muscle with respect to glycogen synthesis from pyruvate.

These investigations confirm the presence of FDPase in human striated muscle. Krebs and Woodford ${ }^{6}$ consider that its role in muscle is limited to the conversion of phosphorylated precursors, particularly $\alpha$-glycerophosphate, because an energy barrier exists for the direct

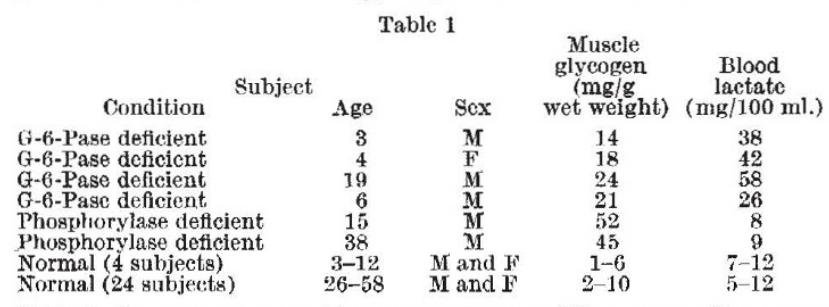

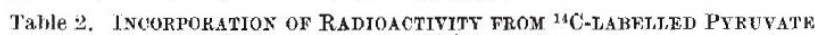
or Bicarbonate into Muscle Glycogen

C.p.m./100 mg glycogen (range)

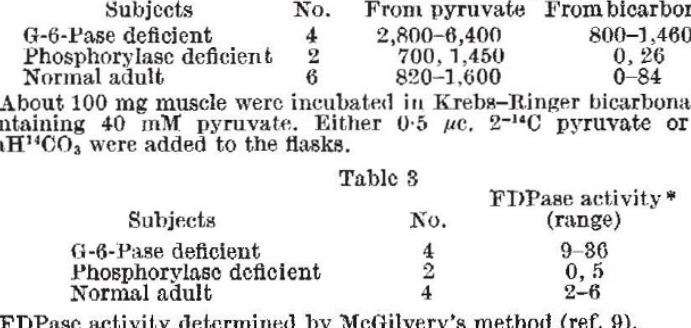

FDPasc activity determined by McGilvery's method (ref. 9).
* Expresged as umoles phosphate produced per g fresh tissue in $20 \mathrm{~min}$. phosphorylation of pyruvate to phospho-enolpyruvate, and that it therefore plays only an insignificant part in the synthesis of glycogen from pyruvate. In the liver, this barrier is circurnvented by the enzymos of the 'dicarboxylic acid shuttlo'11; in this pathway, carbon dioxide combines with pyruvate to form oxalacetate, which is then converted, via malate, to phospho-enolpyruvate. In normal muscle, the activity of the enzymes of the shuttle is less than the sensitivity of the methods at present available for the assay ${ }^{12}$. However, the fact that not only pyruvate but also significant amounts of labelled bicarbonate (Table 2) can be incorporated into muscle glyeogen under certain conditions suggests that they are probably also present in normal muscle. These vestigial pathways in muscle may become more active under the influence of high pyruvate and lactate concentrations and play a part in the metabolic homeostasis of the body.

This work was supported in part by a grant-in-aid from Eli Lilly and Company, Indianapolis, Indiana.

Department of Medicine,

R. MAHLER

Guy's Hospital,

London.

${ }^{1}$ Cori, C. F., Physiol. Hev., 11, 143 (1931).

${ }^{2}$ Solomon, A. K., Vennesland, B., Klemperer, F. W., Buchanan, J. M., and Hastings, A. B., $\boldsymbol{J}$. Biol. Chem., 140, 171 (1941).

${ }^{3}$ Krebs, H. A., Johns Hopk. Hosp. Bull., 95, 19 (1954).

¿ Weber, G., and Cantero, A., Cancer Res., 19, $763(1959)$.

${ }^{5}$ Newsholme, E. A., and Randle, P. J., Biochem. J., 83, 387 (1962).

- Krebs, H. A., and Woodford, M., Biochem. J., 94, 463 (1965). ${ }^{7}$ Field, R. A., in The Metabolic Basis of Inherited Disease, edit. by Stanbury,
J. B., Wyngaarden, J. B., and Fredrickson, D. S. (MeGraw-Hill, 1960). ${ }^{8}$ Mahler, R. (unpublished observations).

${ }^{9}$ MeGilvery, R. W., Methods in Enzymology, 2, 543 (1955).

${ }^{10}$ Schmid, R., and Mahler, R., J. Clin. Invest., 38, 1040 (1959).

"Lipmann, F., Advances in Enzymology, 1, 99 (1941).

${ }^{12}$ Utter, M. F., Ann. N.Y. Acad. Sci., 72, 451 (1959).

\section{Conversion of Alcohol to Ethyl Esters of Fatty Acids by the Lactating Goat}

Freshuy secreted milk contains a lipogenic principle that will incorporate fatty acids into the ester lipids of the milk ${ }^{1}$. While investigating this principle with the aid of palmitic-1 ${ }^{14} \mathrm{C}$ acid and thin-layer chromatographic analysis of the resulting labelled lipids, we noted a prominent spot on autoradiograms between the solvent front and the position of the triglycerides (Fig. 1). The position of this unknown substance was very close (following) to that of the cholesterol esters. It occurred to us that this spot might result from ethyl palmitate- $1{ }^{14} \mathrm{C}$, since the labelled compound was dissolved in ethanol (usually $250 \mu \mathrm{l}$.) to facilitate dispersion in the milk. Further investigation confirmed this contention. The radioactive unknown substance exhibited $R_{F}$ values similar to authentic ethyl palmitate with three different thin-layer chromatographic solvent systems. When the area of a plate containing the unknown was extracted and this extract injectod on to an appropriate gas chromatographic column, 45 per cent of the activity measured in the unknown spot was trapped during the time ethyl palmitate would have emerged from the column. Since this recovery value results, in part, from losses in the syringe, in the column, by detector leaks, etc., the major activity is concluded to have moved in correspondence with ethyl palmitate.

Similarly, conversion of stearic acid to its ethyl ester was observed when it was dispersed with ethanol in the milk system, and both stearate and palmitate showed two closely moving spots when the ethyl esters were separated on thin-layer platcs by a $60: 40$, hexane-benzene solvent system (data not shown). The capacity of the lipogenic milk system to convert stearate to olcate has becn reported ${ }^{2}$.

These findings regarding ethyl ester formation led us to consider in vivo alcohol metabolism and the problem of alcoholism. Two experiments were performed on cach 